\title{
¿Es Max Weber realmente irrelevante? *
}

\section{Ezra Suleiman **}

«Nuestro objetivo es conseguir que el gobierno federal en su conjunto sea menos caro y más eficiente, y cambiar de la cultura de nuestra burocracia nacional de la complacencia hacia la adopción de iniciativa y el empowerment (su adquisición de poder). Tendemos a rediseñar, a reinventar y a refortalecer a todo el gobierno federal en su conjunto.»

\section{Presidente Bill Clinton ${ }^{1}$}

El movimiento de reinvención, que alguna gente, tanto de dentro como de fuera de Estados Unidos, cree que ha afectado al mundo como el fuego salvaje, ha buscado alterar nuestras nociones acerca de qué deben hacer los gobiernos y cómo deben hacerlo. En la mayor parte de los análisis de las reformas burocráticas estos objetivos a menudo se juntan como uno solo. Sin embargo, deben ser separados y deben de mantenerse claramente diferenciados porque la cuestión de qué debe el gobierno hacer es de forma ineludible una cuestión normativa, mientras que la cuestión relativa a cómo debe llevar a cabo las tareas que le han sido atribuidas es en cambio una cuestión esencialmente gerencial. Explicaré, más adelante, por qué el recelo existente a separar el qué deber bacer de las preguntas relativas al cómo no es un fortuito y por qué aquellos que se encuentran al frente del movimiento para «poner fin a la burocracia tal y como la conocemos» y volver a «el poder del pueblo», pueden estar interesados no sólo de forma incidental en las reformas gerenciales. En otras palabras, es si «la tendencia a introducir una gestión más de negocios en el gobierno... está más inspirada por el Zeitgeist ideológico que por un razonamiento científico» ${ }^{2}$.

Este trabajo se enfrenta con dos cuestiones, ninguna de las cuales se trata aquí con suficiente detalle: una constituye el intento de revolucionar la forma en que las burocracias se organizan; la otra se refiere a la forma en que se debilitan las buro- cracias como instrumentos del Estado. Ambas no dejan de estar relacionadas entre $s^{3}{ }^{3}$.

\section{La reinvención: una invención norteamericana}

Poco después de convertirse en presidente, Bill Clinton creó con mucha fanfarria la Asociación Nacional para Reinventar el Gobierno. Ésta iba a ser la clarinada de una revolución en la forma en que el gobierno funcionaba. La misión de esta asociación era crear un gobierno que «funcione mejor, cueste menos, y obtenga los resultados que le interesan a los americanos» ${ }^{4}$. Para abrir camino al logro de este objetivo que sonaba como algo más o menos inocuo, el presidente Clinton creó, en marzo de 1993, el «National Performance Review». Unos cientos de funcionarios fueron escogidos y asignados a dos grupos diferentes. Uno de éstos había de analizar las agencias federales individuales, mientras que al otro se le pidió que analizara la gestión, el presupuesto y las políticas de personal del gobierno federal. También se pidió a las agencias que crearan «labo. ratorios de reinvención» cuya labor era presentar recomendaciones.

El objetivo de modernizar y reinventar cómo debería servir a la sociedad el gobierno, ha pasado a ser considerado una de las contribuciones principales de la administración de Clinton y a ser considerado del mismo modo un evangelio o ideología que los Estados Unidos puede exportar. «La reacción a lo largo de las diferentes localizaciones», tal y como señala Ste- 
ven Kelman, gestor anteriormente en la Oficina de Políticas de Gestión a su vez enmarcada en la Oficina de Presupuesto y Gestión, «ha resultado ser bastante similar desde una perspectiva gerencial o de Administración pública. De forma esencial, en todo el mundo occidental, la fórmula adoptada por la reinvención de la gestión ha sido la de una deburocratización, el establecimiento de menos leyes y empowerment (adquisición de poder) ${ }^{5}$.

La pregunta que es necesario que nos hagamos es la de ¿a qué nos referimos con «reinventando el gobierno»? Si con ello nos referimos a un gobierno que «funcione mejor» $\mathrm{y}$ «cueste menos», esto no es nada excepcional, ya que éste ha sido la base de las áreas de gestión y administración pública desde su inicio. Si, por el contrario, por reinvención entendemos, tal y como sugiere KELMAN, «el establecimiento de menos reglas» y empowerment (adquisición de poder) (no queda claro de quién se produce esa adquisición de poder), entonces hemos pasado, de cuestiones relativas a la gestión, a cuestiones relativas a la política.

Algunos analistas han sugerido que las políticas pueden separarse de la política. Pese a que éste es rara vez el caso, dado que las políticas implican la toma de decisiones de política, el caso de la reinvención del gobierno sugiere que las políticas y la política pueden perfectamente enmascararse por medio de su conversión en cuestiones de gestión. ¿Es el gobierno de reinvención un hijo de tiempos políticos determinados? ¿O, por el contrario, es un nuevo intento más, aunque más convencido, de reducir los desperdicios burocráticos y el aumentar la eficiencia?

Necesitamos saber qué es lo que tiene que ser reinventado. ¿Es acaso nuestro concepto respecto a cómo debería organizare el gobierno lo que debe ser reinventado? ¿O es nuestra visión de que las agencias no deberían seguir organizándose en torno a líneas jerárquicas? ¿O quizás que los gobiernos necesitan adoptar técnicas más eficientes de gestión? Si los objetivos son hacer al gobierno más efectivo y mejorar la relación costeefectividad, quizás la reinvención es simplemente una caracterización hiperbólica.

El debate público respecto de las burocracias públicas es bastante confuso. Tal y como señala James Q. WILsoN, «los liberales que quieren que el gobierno juegue un mayor papel en la sociedad a menudo tienden a minimizar los problemas creados por el gobierno burocrático o asumen que los problemas se resuelvan simplemente gastando más dinero, construyendo mayores facilidades, contratando a gente más preparada, o dotando a los clientes de estas agencias de más derechos. Los conservadores que quieren que el gobierno juegue un papel menor en nuestras vidas critican a los liberales por su optimismo erróneamente orientado respecto de la naturaleza del gobierno burocrático y piden con urgencia que se limite a la burocracia, pero a menudo aplican su crítica a la burocracia de forma inconsistente: "Tengamos menos oficinas de bienestar social, pero tengamos un ejército mayor" ${ }^{\prime}$.

No se puede negar el hecho de que el ataque norteamericano a su propia burocracia ha tenido un efecto muy importante por todo el mundo. Pero la cuestión de hasta qué punto se ha admitido y aceptado ha variado de forma considerable de una sociedad a otra.

\section{Reformando el Gobierno: análisis comparado}

La reforma administrativa ha «alcanzado la mayoría de edad ${ }^{7}$, a medida que las reformas del sector público que comenzaron en los años ochenta se aceleraron y extendieron por todo el globo en los años noventa. En una reciente reunión ministerial de la OCDE sobre la reforma del sector público, todos los países miembros informaron que habían estado involucrados en algún tipo de reforma administrativa ${ }^{8}$. Mientras que el grado y la naturaleza exacta de estas políticas varía de un país a otro enormemente, hay temas comunes claros en este tipo de reformas que se producen en países de la OCDE. Vincent WRIGHT identifica ocho tendencias: reducir el tamaño, alcance y la influencia directa del sector público nacional; mejorar la capacidad de monitorización de la Administración; reformar la gestión del sector público, desmantelar los marcos estatutarios tradicionales del funcionariado; democratizar al sector público; hacer que el usuario del sector público lo sea de forma amistosa; reorganizar las estructuras gubernamentales, y transformar la cultura administrativa ${ }^{9}$. Una de las motivaciones comunes que va más allá de esta reforma es la de mejorar la capacidad de responder de la burocracia frente a los ciudadanos y frente a sus representantes ${ }^{10}$, pero una segunda motivación quizá más importante es la presión fiscal. El hacer más con menos, se ha convertido en el objetivo (mantra) de los gobiernos en los países industrializados más avanzados.

Una aproximación a establecer recortes en los presupuestos ha sido el reducir el número de empleados del gobierno. En los años ochenta, Gran Bretaña, EEUU, Nueva Zelanda, Canadá y Australia anunciaron sus planes de recortar de forma sustancial el número de funcionarios ${ }^{11}$. En los años noventa se adoptaron medidas similares en países tan diversos como Grecia, Portugal, los Paises Bajos, Finlandia, Suecia, Dinamarca, Francia e Italia ${ }^{12}$. Los recortes se han producido bien por medio de ataques directos al funcionariado o bien como derivados de otras reformas. En 1994 una ley en EEUU imponía un recorte del $12 \%$ del número total de funcionarios a nivel federal 
empleados para 1999. En contraste con esto, el Reino Unido en la actualidad carece de un programa específico de reducción de fuerza de trabajo, pero los esfuerzos por racionalizar las funciones del gobierno y por imponer un presupuesto a las agencias han resultado en reducciones de personal. En Suecia, un plan de reducción del empleo público implementado entre 1989 y 1991 tenía como objetivo reducir el empleo en un $23 \%{ }^{13}$. La continua reestructuración de los ministerios también ha traído consigo recortes de personal ${ }^{14}$.

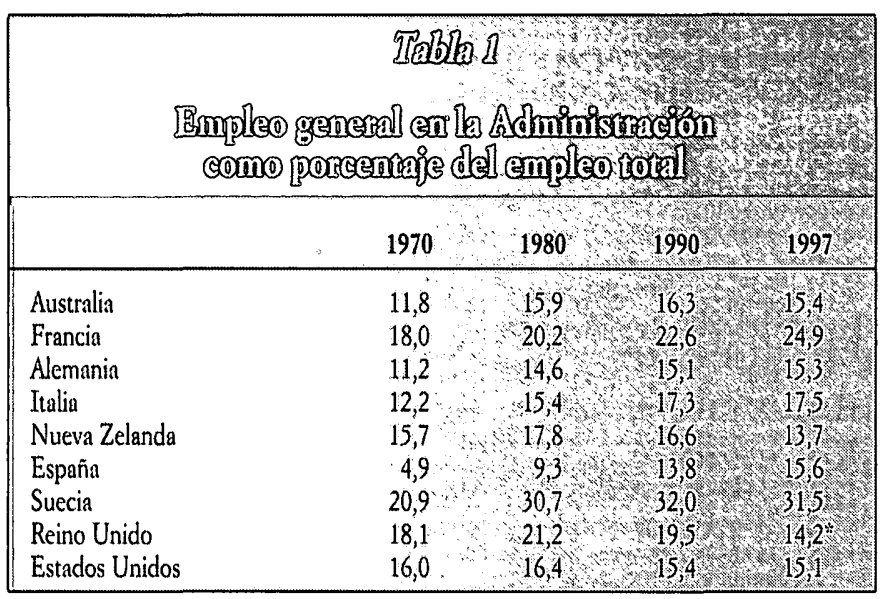

- Cifra para el Reino Unido de 1995.

Fuente: OCDE.

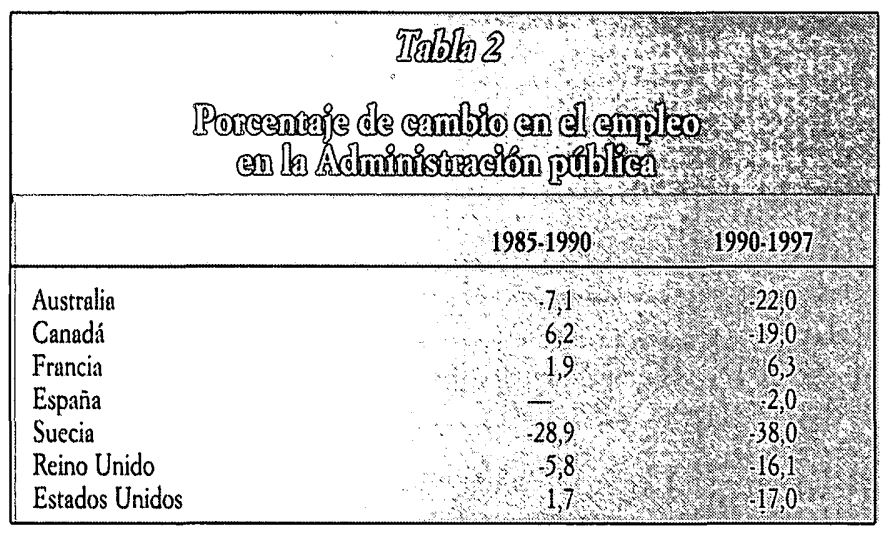

Fuente: Structure of the Civil Service Employment in Seven OECD Nations (Paris, OCDE, 1999).

Tal y como se refleja en las Tablas 1 y 2 , los efectos cumulativos de estos recortes han sido dramáticos en algunos países, mientras que en otros hay menos evidencia de que se haya producido un cambio en el tamaño del gobierno y en la contratación de funcionarios. En Suecia, en los años noventa se produjo una caída dramática en el $38 \%$ del empleo del funcionariado público, mientras que en Francia, el número de funcionarios como porcentaje total del empleo, de hecho creció en un $6,3 \%$ en el mismo período. En Nueva Zelanda y en el Reino Unido, los recortes en los puestos de trabajo en el gobierno sí que ocasionaron algunos ahorros presupuetarios en términos de compensación de costes, tal y como se muestra en la Tabla 3.

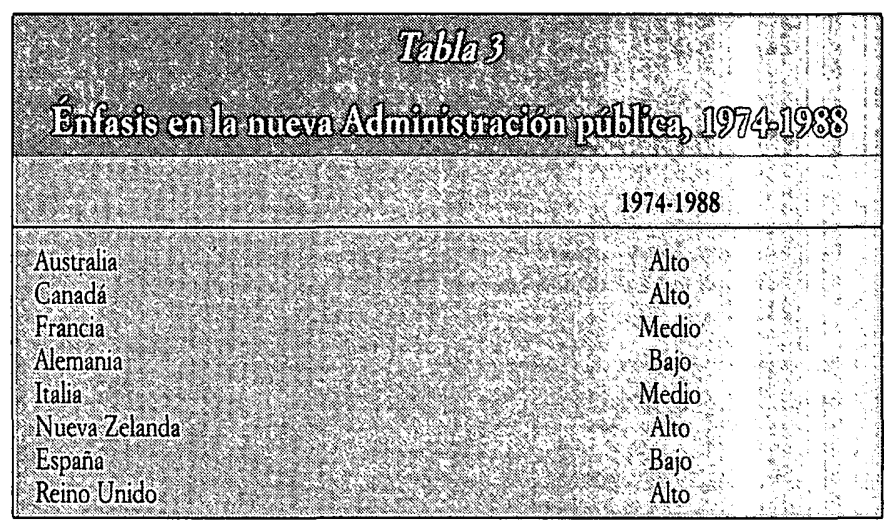

Fuente: Christopher Hood, «Exploring Variations in Public Management Reform of the $1980 \mathrm{sw;}$ en Hans A. G. B. BEXKE, James L. PerRY y Theo A. J. TooneN (eds.), Civil Service Systems in Comparative Perspective (Bloomington, Indiana, Indiana University Press, 1996), 277.

Esto es particularmente cierto en el caso de Nueva Zelanda, donde el tamaño del servicio público se redujo en un $60 \%$ en la primera década de la reforma ${ }^{15}$. Entre 1980 y 1997 , el empleo en el sector público como porcentaje del empleo total cayó del $17,8 \%$ al $13,7 \%$, mientras que los gastos del gobierno como porcentaje del PIB cayeron del 57,6\% en 1990 al 45,5\% en 1997. En el Reino Unido, hubo caídas domésticas similarmente dramáticas en los niveles de empleo público: el empleo a nivel del gobierno en general cayó de 18,1 del empleo total en 1970, al $14,2 \%$, mientras que los puestos de trabajo de funcionarios bajo del $16,1 \%$ entre 1990 y 1997 . Un estudio muestra que entre 1979 y 1990, uno de cada cinco funcionarios había desaparecido. El grueso de estos recortes estuvo en el departamento de defensa y afectó especialmente a los recortes en el personal de blue collar, o si no resultó en una reclasificación del personal a otras secciones del sector público ${ }^{16}$. Sin embargo, los intentos por parte del gobierno conservador de recortar el gasto público han tenido menos éxito: los recortes más dramáticos en el gasto público de las tres últimas décadas se llevaron a cabo por la labor del gobierno de 1974 a $1979^{17}$.

Gran parte del éxito en el recorte del empleo gubernamental en el Reino Unido y en Nueva Zelanda refleja la magnitud de programas de privatización en estos países. El Reino Unido se ha involucrado en la privatización más extensa desde 1979, en lo que WRIGHT describe como «la mayor transferencia de propiedad en el país desde la disolución de los monasterios por Enrique VIII» ${ }^{18}$. Esos esfuerzos privatizadores han continuado en los años noventa; mientras que en 1979 las industrias nacionalizadas tenían un valor del 9\% del PIB, ya en 1997 comprendían menos del $2 \%$ del PIB. Francia fue el único país que llevó a cabo privatizaciones sustanciales en los años ochenta. Un gobierno de centro derecha, desde 1986 a 1988, privatizó 15 trusts industriales, bancarios y financieros ${ }^{19}$. Fuera de la 
Europa Occidental, la ley de Nueva Zelanda State Owned Enterprise Act de 1986 creó el marco legal para introducir principios comerciales en las empresas públicas para poder inyectar prácticas propias del mercado privado en las operaciones. A esto le siguieron esfuerzos para privatizar las industrias para incrementar los ingresos que pudieran ayudar a cubrir ámbitos en los que el presupuesto se quedaba corto. Entre 1985 y 1994, más de veinte empresas públicas (u otras empresas principales) se privatizarón ${ }^{20}$. En Australia, se impulsaron similares esfuerzos de privatización a finales de los ochenta, de nuevo, para combatir déficit presupuestarios ${ }^{21}$. Los esfuerzos de privatización se extendieron por Europa en los años noventa, con la ley francesa de privatización de 1993, el programa italiano que comenzó en 1993, los esfuerzos portugueses por privatizar las utilidades públicas llevados a cabo desde 1990, la reformas españolas a principio de los noventa, la privatización de Alemania Occidental entre 1990 y 1994, y las reformas suecas que llevaron a la venta de acciones en 20 compañías que pertenecían al gobierno entre 1991 y $1994^{22}$.

Otra técnica empleada para disminuir el sector público a nivel federal y nacional ha sido la de descentralizar los programas a los niveles locales del gobierno, o, quitar los servicios públicos del ámbito de las provisiones directas del gobierno. En Bélgica, España, Italia, Francia, Noruega, Suecia, y Dinamarca ha habido esfuerzos sustanciales para descentralizar los servicios públicos, bien a nivel regional, o departamental, o municipal ${ }^{23}$. En Nueva Zelanda, desde finales de los años ochenta, la prestación de servicios tales como los servicios de salud o de bienestar social se ha contratado cada vez más mediante grupos privados y sin ánimo de lucro ${ }^{24}$. En una tendencia que se remonta al menos a 1945, muchos países de la OCDE han depositado su confianza en formas indirectas de Administración pública para realizar funciones estatales utilizando lo que el mundo anglosajón denomina «quagos» (cuasi-organizaciones gubernamentales) y «quangos» (cuasi-organizaciones no gubernamentales) ${ }^{25}$. En algunos países el papel de estas organizaciones ha crecido en los últimos años. Durante los años de gobiernos conservadores, en el Reino Unido, estos cuerpos no electos se utilizaron por el gobierno central para eludir a las autoridades locales. Al estar los «quangos» fundados por la autoridad central y responder ante ésta, han servido como instrumento para endurecer el control central sobre las políticas locales. De forma más general incluso, los esfuerzos británicos para tratar de centralizar la Administración y el control político han resultado ser contrarios a las tendencias que se han dado en la mayor parte de los países occidentales a llevar un mayor grado de responsabilidad a los gobiernos locales ${ }^{26}$.

Junto a estos esfuerzos por reducir de forma directa el tamano del gobierno, los reformistas han intentado hacer que las estructuras gubernamentales existentes funcionen mejor. Muchas de estas políticas se enmarcan bajo la rúbrica de New
Public Management (NPM). Tal y como ha definido el NPM el Comité de Gestión Pública de la OCDE, es «un nuevo paradigma de la gestión pública... dirigido a fomentar una cultura orientada a la actuación en un sector público menos centralizado» ${ }^{27}$. En su base, el NPM va dirigido a mejorar la actuación del gobierno y de sus gerentes ${ }^{28}$. El NPM implica poner un especial énfasis en la gestión por encima de las políticas; en organizar el gobierno en grupos de agencias y de departamentos, más que en pirámides tradicionales y jerarquizadas; en adopción de toma de decisiones estratégicas y orientadas a la obtención de resultados, utilizar objetivos de output, indicadores del rendimiento, pagos en relación con los resultados y medidas de mejora de la calidad; en recortar los gastos en vez de crear nuevos; en una mayor flexibilidad; en una mejora de la eficiencia en la prestación de servicios públicos; en la promoción de la competencia en el ámbito y entre organizaciones del sector público ${ }^{29}$. Mientras que todos los países de la OCDE están involucrados en alguna forma de NPM, la extensión actual de esto varía en gran medida, tal y como se muestra en las Tablas 3 y 4. Mientras que los países anglosajones han promovido reformas de altos vuelos permitiendo la reinvención del gobierno o descartarlo del todo, muchos de los países escandinavos también se han involucrado en importantes esfuerzos reformistas. Por ejemplo, tanto en Dinamarca como en Suecia las reformas del NPM, tanto a nivel nacional como a nivel local han sido importantes desde mediados de los años ochenta ${ }^{30}$. La OCDE clasifica a Francia como un reformador NPM de rango medio, mientras que otros argumentan que el NPM ha estado relativamente ausente de las reformas de la Administración públi$\mathrm{Ca}^{31}$. En cualquier caso, ha habido escasas críticas a la eficiencia del gobierno y se ha defendido al NPM como una panacea. Sin embargo, ha habido reformas, de forma más notable, la descentralización del gobierno en 1982. De forma adicional, los años ochenta han sido testigos de un creciente énfasis en la provisión de servicios y en la capacidad de responder de los prestadores de éstos frente a los ciudadanos, culminando en la creación de «centres de responsabilités en 1989 y la Carta del Servicio Público entre 1990 y 1991. Desde 1995, el Pre-

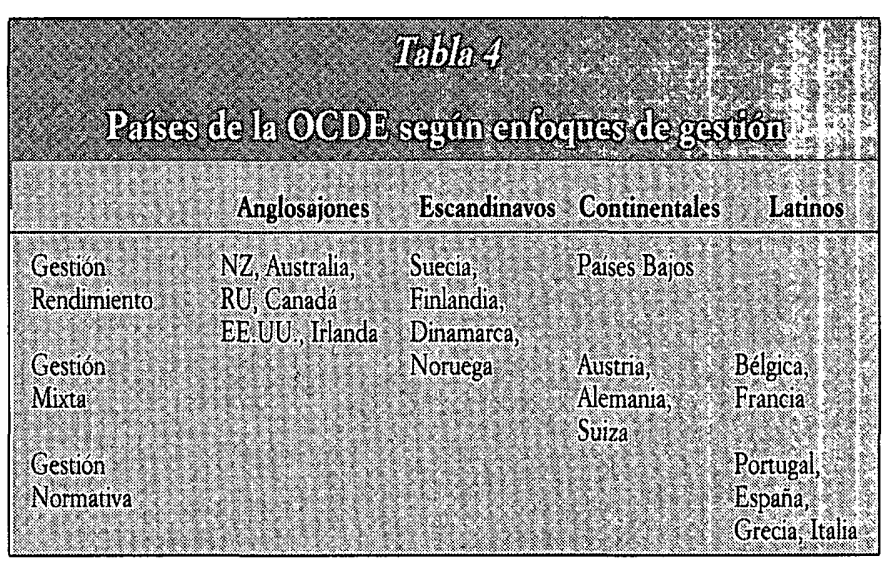

Fuente: PUMA, In Search of Results. Performance Management Practices (Paris, OCDE, 1997) 
sidente Chirac ha puesto un énfasis renovado en las reformas de la gestión pública, y en 1996 creó un comité ministerial para la reforma estatal dirigido a políticas de reformas ${ }^{32}$.

Nueva Zelanda y, en menor grado, el Reino Unido son ejemplos de los esfuerzos más radicales de reforma. En el caso de Nueva Zelanda, la victoria del gobierno laborista en 1984 trajó al poder a un gobierno decidido a utilizar la reforma del sector público como instrumento para estancar los déficit públicos y restaurar la competitividad internacional que falta en la mayoría de los países restantes, donde las reformas tienden a ser esporádicas y desconectadas de todo tipo de visión ideológica mayor ${ }^{33}$. Las reformas de Kiwi han ido dirigidas a separar las funciones comerciales de las no comerciales, a dividir las consultivas de las administrativas, a introducir principios competitivos en el sector público, a permitir una gran discrecionalidad gerencial en un sistema de gobernabilidad (governance) más descentralizado ${ }^{34}$. El objetivo es «dejar a los gestores gestionar», reduciendo las coacciones que se les han impuesto y dirigiendo sus miradas de los inputs a los outputs. Los gestores disponen así de una mayor libertad para utilizar los recursos como deseen, y el nuevo sistema presupuestario impone límites globales dentro de los cuales los gestores pueden gastar libremente ${ }^{35}$. Mientras que los analistas externos han identificado la existencia de continuos problemas a la hora de implementar y, en especial, a la hora de evaluar los efectos de las reformas, parece haber un cambio claro e incluso éxito en las reformas. La evaluación de Allan ScHICK sobre el programa de Nueva Zelanda estableció que «existe casi un acuerdo universal respecto a que el gobierno neozelandés se gestiona mucho mejor ahora que antes» ${ }^{36}$.

En el Reino Unido se ha producido una reforma administrativa que comprende prácticamente lo mismo que comenzó en $1979^{37}$.

Las reformas se pueden resumir como reformas que abarcaban privatización, eliminación de subsidios, marketización, consumismo y descentralización en la gestión ${ }^{38}$.

Un período inicial de reforma, de finales de los años setenta hasta 1988, enfatizó el recorte de los costes y la eliminación de lo inútil. Esto acarreó un endurecimiento de los controles sobre el funcionariado (mediante límites en el dinero en metálico, planificación de éste, un mayor control sobre el pago a los funcionarios, y recortes en el funcionariado), descentralizando las responsabillidades, y por medio de esfuerzos para fijar objetivos claros que serían evaluados con indicadores del rendimiento ${ }^{39}$. Una de las reformas más notables durante este período fue la «Financial Management Initiative» (FMI), que comenzó en 1982 y requirió que los departamentos midieran su actuación frente a esos claros objetivos manifestados ${ }^{40}$. Después de 1988, las reformas británicas reflejaron las bases filosóficas de la nueva economía institucional. El gobierno trató de introducir estructuras con incentivos y la competición de mercado en el sector público. Esto acarreó una proliferación de agencias, privatización, contratación fuera, evaluación de mercado y reformas respecto del personal de gestión ${ }^{41}$. El más conocido y aunque de forma discutida, el cambio con mayor éxito en este período ha sido «Next Steps Initiative», que creó agencias semi-autónomas que estarían más distantes del gobierno central y, por tanto, libres para gestionar sus propios asuntos ${ }^{42}$. Para 1997 , el $72 \%$ de los funcionarios trabajaban en agencias Next Step ${ }^{43}$.

En otros países, el ritmo de la reforma ha sido más lento. En Alemania, por ejemplo, la mayor parte de la reforma se ha llevado a cabo a nivel regional y local, con muchas menos iniciativas de reforma a nivel nacional. Solamente desde finales de los años ochenta se ha podido apreciar un resurgimiento en las discusiones y un creciente consenso político, acerca de la necesidad de una reforma fundamental del sector público a nivel federal ${ }^{44}$. En julio de 1995, la creacion del «Lean State» (Schlander Staat) «Advisory Council», institucionalizó los esfuerzos de reforma federal. Se le encarga examinar las funciones del gobierno, recomendar recortes en las actividades ministeriales, o recomendar formas de transferirlas a autoridades subordinadas, y proponer la privatización y la reforma de las regulaciones ${ }^{45}$. Sin embargo, la gran mayoría de las reformas se llevan a cabo a nivel del Länder o a nivel local, más que al nivel federal ${ }^{46}$. Se puede decir que un $70 \%$ de. las comunidades locales en el viejo y pre-unificado Länder están involucradas en algún tipo de reformas en las líneas de lo que se conoce como el New Steering Model (NSM), con varios gobiernos Länder apoyando estos experimentos ${ }^{47}$. Al igual que las reformas del NPM, las reformas del NSM han acarreado esfuerzos para mejorar el servicio a los «clientes», a la vez que esfuerzos para introducir un pago relacionado con el rendimiento y prácticas de personal más flexibles, e utilizar técnicas de «Total Quality Management», mejorar los presupuestos y los métodos de contabilidad, descentralización y los esfuerzos para llevar a cabo medidas de actuación e indicadores de output ${ }^{48}$.

Tal y como muestran estos ejemplos, en el centro de gran parte de la reforma del sector público ha estado el deseo de rehacer el funcionariado convirtiéndolo en un cuerpo de gestores que mejoraran la eficiencia y el servicio, a la vez conseguirán seguir adelante con presupuestos más pequeños. Un cierto número de países han tratado de utilizar las reformas en la normativa del funcionariado para producir precisamente este nuevo animal gerencial. En Nueva Zelanda, la Ley del Sector Estatal de 1998 vino a sustituir a los funcionarios permanentes que encabezaban los departamentos gubernamentales por Altos Ejecutivos ( $\mathrm{CE}=$ Chief Executives) que son nombrados para que ocupen puestos con contratos por un período de cinco años. Sus nombramientos van unidos a acuerdos de actuación y un informe sobre el rendimiento anual evalúa su progreso. $\mathrm{Al}$ mismo tiempo, a los CEs se les ha concedido mayor dis- 
crecionalidad respecto del pago y de las condiciones de empleo para aquellos que estén en sus departamentos. La Ley de Financiación Pública de 1989 hizo que el gobierno comprara outputs, incluyendo consejos respecto de políticas, de los departamentos a precio de mercado ${ }^{49}$. KETTL ha resumido la nueva situación de la siguiente forma: «el trabajo individualizado y los contratos de actuación han venido a sustituir el sistema de funcionariado basado en las normas y el procedimiento. Los gestores del gobierno han contratado en base a contratos con términos fijos y negocian los outputs de sus agencias con los ministros» ${ }^{50}$. También ha habido cambios sustanciales en el funcionariado en el Reino Unido. Además de importantes recortes en lo que se refiere a su número, las reformas han introducido contratos de trabajo en las áreas administrativas y en los puestos superiores, al igual que una gestión delegada en cuerpos más autónomos y descentralizados, un pago delegado, un reclutamiento y una graduación de una agencia central a los departamentos y a las agencias mismas, y publicado a su vez en el Código de Ética del Funcionariado ${ }^{51}$.

En otros países, la reforma del funcionariado ha resultado ser menos dramática. Las reformas australianas se han centrado más en mejorar el adiestramiento como forma de mejorar la actuación del funcionariado. Sin embargo, desde 1983, los secretarios permanentes han puesto malos gestos frente a los contratos de cinco años, que sustituyen su previo puesto permanente y fijo: ahora estos contratos sólo se pueden renovar si el secretario ha mostrado llevar a cabo una actuación satisfactoria ${ }^{52}$. En EEUU, la reforma del funcionariado ha sido mucho menos importante, y el sistema funcionarial existente ha permanecido tal cual y sin cambios en los últimos años ${ }^{53}$. En Francia también se han llevado a cabo menos reformas del funcionariado. Las carreras de los funcionarios de carrera siguen estado reguladas por los cuerpos. Mientras que en otros lugares los funcionarios de carrera estaban siendo objeto de desregulación en los años ochenta, en Francia en los años ochenta los socialistas extendieron el sistema a los que estaban bajo contrato. En los.años noventa, ha habido esfuerzos encubiertos de desregular o recortar al funcionariado que se han enfrentado con importantes protestas. La situación ha llevado a un estudioso de la Administración pública a declarar que la reforma del personal de gestión se encuentra en un atolladero ${ }^{54}$.

Algunos países han creado o reformado el ámbito de los altos funcionarios. En el Reino Unido, una ley de abril de 1996 creó el Alto Funcionariado (SCS) que está formado por 3.000 personas que previamente eran Grados 1 a 5 del Funcionariado Doméstico. Los SCS incluyen a todas las agencias de Altos Ejecutivos, y es el grupo de altos responsables para «el gabinete colectivo del gobierno, que conduce el cambio en la gestión, y preserva el profesionalismo y los valores del servicio ${ }^{55}$. En Australia, La Ley del Servicio Público de 1983 creó el Servicio Ejecutivo Superior. A diferencia de Nueva Zelanda, donde mucha gente nueva se ha unido al SES, en Australia, la mayoría son todavía funcionarios de carrera ${ }^{56}$. Los desarrollos más importantes llevados a cabo en los países de la OCDE que afectan al alto funcionariado se resumen en las Tablas 5 y 6 .

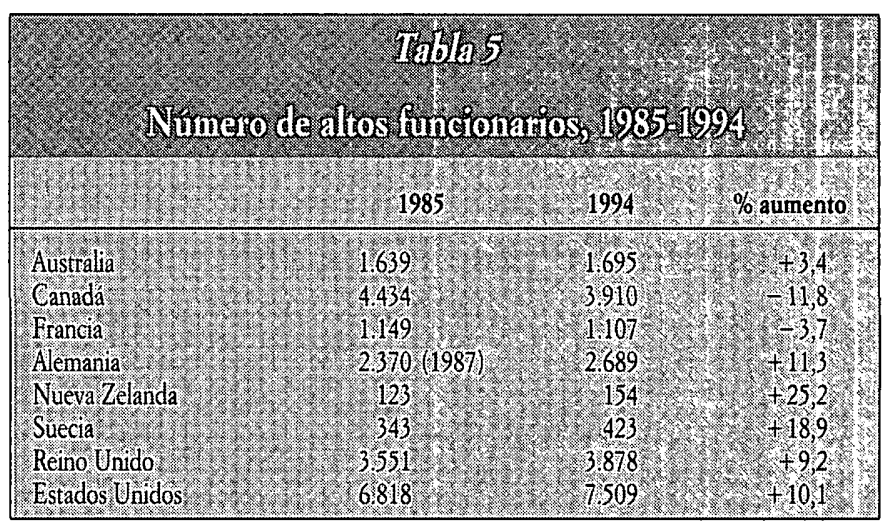

Fuente: OCDE: Managing the Senior Public Servive. A Survey of OECD Countries (1997).

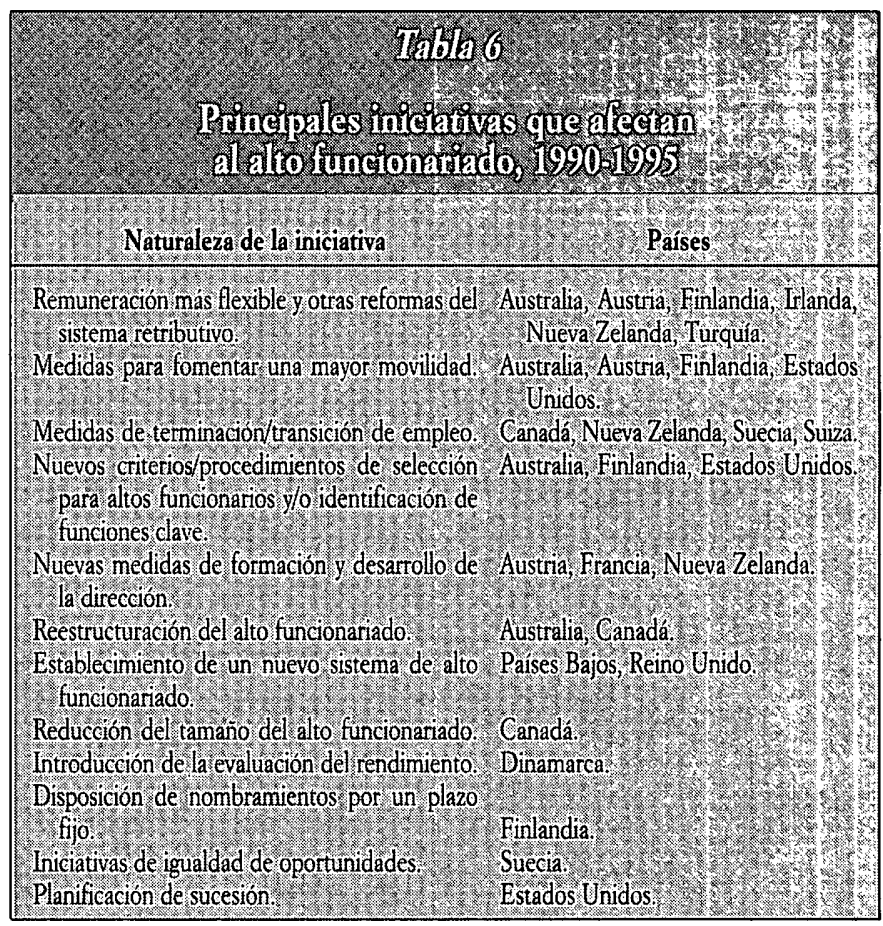

Fuente: OCDE, Managing the Senior Public Service. A Survey of OECD Countries (1997).

Con vistas al sector privado como modelo de cómo las agencias gubernamentales deberían autogestionarse, los gobiernos han tratado de rehacer las prácticas de evaluación de políticas con la esperanza de realzar la eficiencia y mejorar la prestación de servicios al público. Una manifestación de esta tendencia ha estado en los esfuerzos llevados a cabo para evaluar las políticas gubernamentales en términos de outputs en vez de en términos de input, y en los esfuerzos por desarrollar medidas que puedan reflejar esto de la mejor forma. Esto ha resultado ser 
uno de los mayores retos de las reformas del NPM. Resulta irónico que el movimiento de NPM no haya podido con carácter general desarrollar buenas medidas para los propósitos de la evaluación. Tal y como ha concluido otro autor, «gran parte de las características más celebradas del new public management... son virtualmente imposibles de medir» ${ }^{57}$. Tanto si las reformas se miden atendiendo a outputs (es decir, número y calidad de actividades) o atendiendo a resultados (una medición más amplia de la efectividad), ambas formas resultan difíciles de evaluar. Los neozelandeses se están dando cuenta de que ésta es una de las cuestiones esenciales con la que siguen teniendo que enfrentarse, incluso si se miden únicamente los outputs $^{58}$. Nueva Zelanda ha hecho todo lo posible para tratar de desarrollar indicadores de actuación, pero otros países han realizado esfuerzos similares. El gobierno sueco utiliza informes anuales auditados. La Ley norteamericana de Actuación Gubernamental y Resultados exige que las agencias creen planes estratégicos y encuentren formas para medir los resultados adecuadamente ${ }^{59}$. Varios países han estado experimentando con presupuestos de actuación, y cambiando de una forma de presupuestar basada en el input, y de unos sistemas de contabilidad basados en el dinero en metálico, a presupuesto de actuación y una contabilidad basada en la acumulación de intereses. En la Tabla 7 se muestran los desarrollos recientes llevados a cabo por un cierto número de países de la OCDE. Estos esfuerzos ponen de manifiesto un deseo general de convertir los presupuestos en un instrumento al servicio de la gestión más que un simple instrumento del gasto, aunque en la práctica existe una gran variación en el grado en que los países han alcanzado esto. Nueva Zelanda ha creado ahora el vínculo más próximo entre las asignaciones presupuestarias y las medidas de actuación; la conexión es bastante menos intensa en el caso del Reino Unido e inexistente en Dinamarca ${ }^{60}$.

En Dinamarca y en Finlandia la calidad de la provisión de servicios por el gobierno se mide ahora en base al grado de satisfacción de los consumidores. Por ejemplo, Finlandia hace cada vez un mayor uso de los informes de los clientes y usuarios. Esto pone de manifiesto la existencia en un número importante de países de una meta esencialmente filosófica dirigida a poner un mayor énfasis en los consumidores-usuarios, en la administración del gobierno. Los clientes o consumidores han venido así a sustituir a los ciudadanos. La idea presente aquí es la de hacer a los gobiernos responsables frente a sus clientes en el marco de las operaciones que realizan con éstos ${ }^{61}$. Esto forma parte del esfuerzo por dejar a los gestores gestionarse, con la idea que defiende el construir desde abajo mejoras en la prestación de servicios más que tratar de implementar esto desde arriba. De esta forma, en los EEUU, la administración de Clinton llevó a cabo un esfuerzo para hacer que 214 agencias del gobierno federal definieran los estándares de los servicios ${ }^{62}$. John Major lanzó una Carta de Derechos de los Ciudadanos en 1991 que tenía como objetivo recordar a los funcionarios

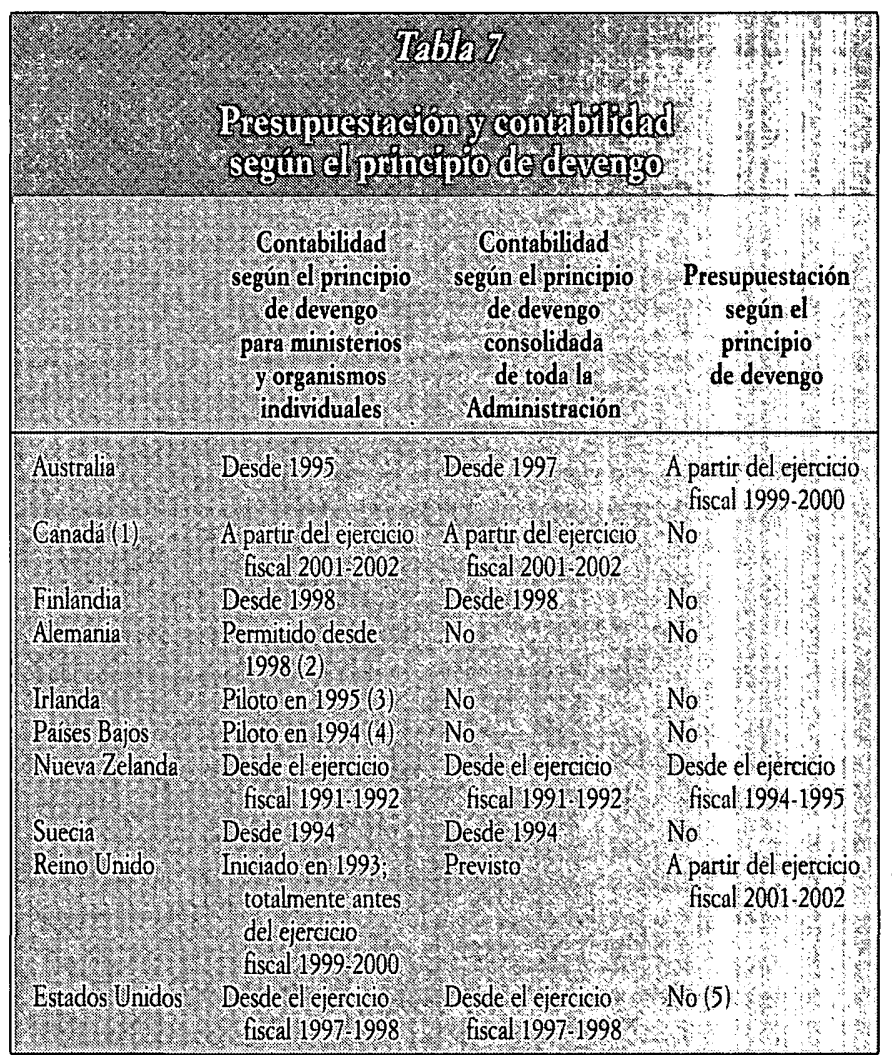

(1) Canadá aplica el principio de devengo modificado a la contabilidad y a la presupuestación.

(2) Ley sobre Principios Presupuestarios modificada en 1998. Ahora a las organizaciones públicas alemanas se les permite explíitamente adoptar principios de devengo además de los principios habituales de contabilidad según el principio de caja.

(3) Un solo ministerio presenta las cuentas según el principio de devengo además de según los requisitos habituales de contabilidad según el criterio de caja.

(4) Los organismos piloto presentan sus cuentas según el principio de devengo además de los requisitos habituales de contabilidad según el criterio de caja.

(5) El principio de devengo se utiliza únicamente para programas de garantías y préstamos en el presupuesto de EEUU.

Fuente: Focus, 12 (París, OCDE, marzo 1999).

públicos sus responsabilidades frente a los «consumidores» y trató de implementar medidas para mejorar la calidad del servicio, y garantizará derechos de apelación ${ }^{63}$.

\section{La «obsolescencia» de Weber}

No resulta tan sumamente sorprendente darse cuenta de que las reformas que buscaban hacer a la burocracia una institución más eficiente, han variado en su alcance y en sus consecuencias. Sin embargo, nos seguimos encontrando con una situación en la que ha surgido una nueva «ideología» que pueden construirse como una ideología anti-weberiana en el sentido de que se basa en la creencia de que la visión de la burocracia de WeBEr no está meramente pasada de moda, sino que es del todo nefaria. La creencia de WEBER, de que las burocracias 
son técnicamente superiores por su «precisión, velocidad y carencia de ambigüedad» es, de acuerdo con la ideología construida, una descripción que «ningún norteamericano se atrevería a aplicar...» ${ }^{64}$. OSBORNE y GAEBLER creen que la burocracia se ha vuelto corrupta porque ya no resulta adecuada para la sociedad contemporánea. Es una forma de organización que era adecuada en una era anterior, pero que tiene poca relevancia en nuestro mundo cambiado y cambiante.

\section{Escriben que:}

El tipo de gobiernos que se desarrollaron durante la era industrial, con sus burocracias perezosas y centralizadas, eran gobiernos preocupados con las reglas y las regulaciones, y las cadenas de dirección de la jerarquía ya no funcionan muy bien que digamos. Consiguieron grandes cosas en su tiempo, en algun momento de su trayectoria se alejaron de nosotros. Se volvieron irregulares, gastosos y poco efectivos ${ }^{65}$.

El concepto mismo de burocracia - lo qué hace y cómo lo hace - se ha atacado. Se observa que la organización jerárquica y centralizada previa a la era de la Segunda Guerra Mundial no funcionaba «bien en la sociedad y economía de los años noventa, que era rápidamente cambiante, rica en información e intensa en conocimientos. Son como lujosos aviones transoceánicos en una era de jets supersónicos: grandes, pesados, caros y muy difíciles de manejar a la hora de darles las vuelta» ${ }^{66}$.

El ataque a las organizaciones públicas modernas ha estado encabezado por EEUU. Ningún otro país, con la excepción posible del Reino Unido, se ha podido equiparar a EEUU en su fervor por dar la vuelta o reinventar las organizaciones que constituyen los instrumentos de los funcionarios electos. ¿Por qué se considera a tales organizaciones perezosas, caras y pasadas de moda en algunos países, pero no en otros? ¿Por qué algunos países (especialmente EEUU) ven la necesidad de deshacerse de instituciones establecidas hace mucho tiempo y crear otras nuevas que las sustituyan mientra que otras simplemente ven la necesidad de llevar a cabo algunas reformas? ¿Si la enfermedad afecta por igual a todas las sociedades, por qué varían tanto los remedios empleados?

Éste no es el ámbito para contestar a todas estas preguntas. Necesitamos previamente para ello entender qué es aquello que se nos presenta como forma de organización alternativa. ¿En qué consiste de forma ostensible la revolución organizacional? Sus principales características y conceptos derivan de la visión de que el Estado presta servicios prácticamente del mismo modo en que una empresa o un despacho vende productos al consumidor. Por tanto, no existe ninguna razón que impida que una agencia pública se someta a las mismas reglas y condiciones a las que se someten todas las empresas privadas.

Este punto de vista no admite ningún tipo de argumentos que justifiquen una diferencia entre el estado y la empresa pri- vada. El hecho de que el Estado pueda tener obligaciones o responsabilidades frente a la sociedad o el hecho de que la colectividad en su conjunto pueda tener intereses que vayan más allá del interés de determinados individuos que forman parte de esa sociedad, es algo que no entra en la ecuación de los reinventores del gobierno.

\section{Más allá del recorte de los costes}

La reinvención de los movimientos del gobierno ha sido un impulso ganador durante varios años. Mientras que los marxistas podían haber renunciado a todo tipo de noción de que el Estado desaparecería, este concepto ha sido adoptado ahora por la derecha. De hecho, algunos trabajos de postura — salidos de la Fundación Hereditaria, por ejemplo- sugieren que se lleve a cabo un completo desmantelamiento de la mayor parte de los Departamentos Federales de EEUU.

\section{El valor de la burocracia}

La búsqueda de las bases de la democracia ha introducido una variedad de definiciones y prerrequisitos. Las predisposiciones, o culturas que perdieron su brillo hace algunos años han reaparecido, bajo diferente guisas con toda seguridad. Los procesos o procedimientos han resultado ser fundamentales para cualquier forma de organización democrática ${ }^{67}$. La confianza o el civismo (o la cortesía), un tema proto-tocquevelliano, ha adquirido recientemente gran importancia en la amplia formación de explicaciones ${ }^{68}$. Entre la amplia variedad de premisas que incluyen un mercado económico, seguridad (económica y física), elecciones competitivas y una sociedad civil fuerte, hay dos que destacan en particular: el Estado de Derecho y que haya un Estado operativo (eficiente y responsable).

Douglass NORTH ha distinguido entre instituciones y organizaciones. Las primeras se refieren a las reglas que «definen la forma en que se juega el juego». Las últimas se refieren a los cuerpos políticos, sociales o educacionales que constituyen «grupos de individuos unidos por un objetivo como de alcanzar determinados objetivos» ${ }^{69}$. Las reglas determinan el tipo de organizaciones que surgen y el papel que eventualmente desarrollaran.

En la actualidad, la institución de la democracia depende de reglas y normas que requieren que la organización del Estado 
asegure que éstas se implementen de la forma correspondiente. Sin el instrumento a su disposición, el Estado no puede garantizar el Estado de Derecho, el imperio de la ley.

¿Es la necesidad con la que se enfrenta una democracia consolidada similar a aquella con la que se enfrenta una sociedad en transición hacia la democracia? Claramente, no. Ya que, para la democracia ya establecida, la institución de una burocracia pública en ocasiones evoluciona de manera que se reduce de forma significante su papel, o se ve forzada a perder legitimidad, o bien se mina su profesionalismo por medio de una excesiva politización de la misma. Para la joven democracia, la cuestión principal a la que se ha de enfrentar es una cuestión de creación; la cuestión de cómo desarrollar en una fase de transición un instrumento burocrático profesional.

¿Por qué la necesidad de un aparato profesional? Simplemente, porque eso es lo que distingue, de acuerdo con WEBER, a un orden patrimonial de un orden racional-legal. Aquello a lo que se refiere WEBER como la variedad «monocrática» ${ }^{70}$ de burocracia, es un desarrollo que acompaña y subyace a todo orden capitalista y democrático. El desarrollo de la burocracia, «en su mayor parte bajo auspicios capitalistas, ha creado la necesidad urgente de tener una administración estable, estricta, intensiva y calculable. Es esta necesidad la que da a la burocracia un papel crucial en nuestra sociedad como elemento central en todo tipo de administración a gran escala» ${ }^{71}$.

Para WeBER, el capitalismo exige la reducción de la falta de certeza y exige también una mayor capacidad para planear y llevar a cabo predicciones en base al conocimiento técnico. Es por ello que el desarrollo de un orden capitalista tiende a ir de la mano con la extensión de las organizaciones burocráticas. «Por otro lado», escribe WEBER, «el capitalismo en sus fases modernas de desarrollo tiende de forma importante a proteger el desarrollo de la burocracia, aunque tanto el capitalismo como la burocracia han surgido de diversas fuentes históricas bien distintas.

A la inversa, el capitalismo es la base económica más racional para la administración burocrática y le permite que se desarrolle de la forma más racional, especialmente porque, desde un punto de vista fiscal, le proporciona los recursos económicos necesarios» ${ }^{72}$.

«La burocracia es superior en conocimiento» ${ }^{73}$, manifiesta WEBER, y esto explica por qué, exceptuando al empresario capitalista, la mayor parte de la población ha «tendido a organizarse en grupos corporativos de gran escala que está inevitablemente sujetos a control burocrático» ${ }^{74}$. Bernard Silberman trata de comprender por qué las burocracias han adoptado diferentes formas y no se atienen estrictamente a una forma «weberiana». Observa mayores diferencias que similitudes en el desarrollo de las burocracias estatales. Mantiene que «no todos los roles burocráticos y todas las estructuras organizacionales terminaron igual» y quiere comprender «por qué un proceso aparentemente universal tenga como resultado formas tan sumamente diferentes» ${ }^{75}$. Las formas burocráticas no desarrollaron como respuesta a los desarrollos del capitalismo, argumenta SiLBERMAN. Pero es evidente que las organizaciones burocráticas sí que se desarrollaron, incluso en diferentes formas, para atemperar la inseguridad del capitalismo. WEBER había sido acusado, por SILBERMAN entre otros, de confeccionar una «lista de lavandería» ${ }^{76}$ de características comunes a todas las sociedades legales-racionales, cuando, de hecho, se produjeron diferentes resultados organizacionales. Silberman busca justificar esos diferentes resultados. Sin embargo, quizás se toma demasiado al pie de la letra las expectativas de la convergencia organizacional. Tampoco da suficiente importancia a la necesidad observable de las organizaciones de Estado a la hora de llevar a cabo funciones propias de una sociedad capitalista-democrática.

Otros han ido más allá a la hora de atacar la teoría de WEBER sobre la relación entre los mercados y la burocracia: De hecho, el colegio de elección pública ha mantenido que la burocracia y la sociedad tienen intereses diametralmente opuestos. El «burócrata» y el bureau se contemplan como figuras que toman «decisiones» que tratan de «maximizar», de la misma forma que cualquier actor trata de hacer. Tal y como observa NisKANEN, no sabemos cómo pensar claramente acerca de la burocracia porque no tenemos una «teoría de bureaus que sea consistente con el concepto instrumental de gobierno, es decir, un concepto de gobierno, que es únicamente un intrumento al servicio de las preferencias de sus constituyentes ${ }^{77}$. Mantiene que el impedimento que se presenta al deducir una teoría de bureaus proviene del hecho de que «lo escrito sobre burocracia, desde Confucio hasta WEBER, procede de un concepto orgánico de Estado, es decir, un concepto de Estado para el que las preferencias de los individuos están subordinadas a ciertos objetivos orgánicos del Estado» ${ }^{78,79}$.

La teoría económica de la burocracia toma el modelo weberiano como tarea para descuidar «el comportamiento económico de los bureaus y cómo afecta a su actuación a la hora de prestar servicios públicos». WEBER se preocupa fundamentalmente por el comportamiento en el ámbito de los bureaus y de las relaciones entre bureaus. Para Niskanen, «Cualquier teoría acerca del comportamiento de los bureaus que no incorpore las preferencias personales de los burócratas... será únicamente relevante en los ambientes más rígidamente autoritarios. De forma fundamental, nuestra confusión contemporánea deriva del fracaso a la hora de conseguir que la burocracia llegue a un acuerdo con el gobierno representativo y con los mercados de trabajo libres».

El mérito de la aproximación económica en la que se basan gran parte de los escritos sobre la reinvención del gobierno y los objetivos de ésta, es que plantea la cuestión de la que se ocupa mi estudio totalmente. ¿Dispone el Estado de obje- 
tivos orgánicos autónomos, o debe contemplarse como un proveedor de servicios para el que es necesario descubrir el equilibrio en los precios?

Trataré con más detalle esta cuestión en un estudio venidero, cuestión que, en el fondo, es una cuestión normativa. Simplemente no hay forma de escapar del hecho de que una teoría económica de la burocracia —o de cualquier cosa a estos efectos- no hace mención ni se preocupa de las cuestiones normativas que las sociedades vienen llamadas a decidir diariamente a través del proceso político. Las economías y las políticas como disciplinas se enfrentan con esta cuestión esencial: la distribución o reparto de los escasos recursos. Pero dejan de estar acompañadas a la hora de enfrentarse a la solución del problema. La economía se guía por un ordenado modelo de alocación de recursos que incluye la ausencia de conflictos humanos visibles, y que mira hacia el mercado para determinar la forma más eficiente de alocar los escasos recursos de la sociedad. La aproximación política lo tiene más difícil a la hora de descuidar a las organizaciones, grupos, representaciones, presiones, elecciones -el engorroso proceso de las políticas democráticas-, todos los cuales determinan cómo se lleva a cabo la distribución de recursos.

La visión de la burocracia de NISKANEN se basa en un simple modelo económico: el burócrata y los bureaus tratan de maximizar sus intereses. En otras palabras, buscan presupuestos muy superiores y un continuo aumento de personal. En su conjunto, la sociedad que paga a estos bureaus, claramente tiene un interés que es diametralmente opuesto al de los bureaus. Por tanto, la burocracia no puede contemplarse simplemente como un instrumento del Estado. Debe contemplarse, de acuerdo con el modelo económico, como «alguien que elige» y como un «maximizador» y como una institución con preferencias y objetivos propios.

Resulta de cierto interés destacar cómo la relativa importancia de las instituciones en las políticas democráticas evoluciona con el tiempo. No hace tanto tiempo, los estudiantes se molestaban en insistir en que el Estado era capaz de actuar como una entidad independiente y autónoma para poder así justificar la noción de las políticas democráticas que difería tanto de la noción de los marxistas como de la noción de los pluralistas. Si se podía enseñar al Estado a actuar de forma independiente a los intereses de la sociedad, si se le podía del mismo modo enseñar a que tuviera intereses propios, entonces se le habría mostrado que no constituía una herramienta al servicio de las fuerzas más poderosas de la sociedad.

De hecho, ha estado de moda - al menos hasta que esta aproximación se abandonó recientemente- clasificar a los Estados en Estados «fuertes»y «débiles» dependiendo de su capacidad para resistir frente a las presiones de la sociedad. Estados tales como Francia y Japón se contemplaron de forma uniforme como Estados «fuertes» porque eran unitarios, centralizados y poseían un aparato burocrático bien adiestrado y listo para implementar las decisiones gubernamentales. La sociedad estadounidense, junto a algunas sociedades subdesarrolladas, siempre se contempló como un Estado descentralizado y fragmentado. La implicación de esta dicotomía era que un Estado fuerte podía determinar la alocación de recursos y adoptar sus decisiones sin estar sujeto a las presiones que provenían de los grupos sociales más poderosos. Un Estado débil no podía actuar de forma independiente de los grupos dotados con grandes recursos.

Lo que, entre otras cosas, determinaba, que un Estado fuera «fuerte» o «débil» dependía del tipo de instrumento que estuviera a su servicio. El tipo de máquina burocrática que posea un Estado es una importancia quintaesencial para la forma en que una política democrática se conduce a sí misma.

\section{Burocracia y democracia}

NISKANEN defendió que la pregunta realmente importante respecto de la burocracia - y a la que trataba de dar respuesta su libro- era: «¿Qué presupuesto y qué comportamiento de output debería esperarse de bureaus bajo circunstancias diferentes?» ${ }^{80}$. Resaltó que los anteriores escritores sobre el tema de la burocracia - WeBER, von Mises, TulLOCK, Downs- se habían aproximado mucho a las preguntas fundamentales relativas a la burocracia pero sin llegar realmente a plantearlas. NisKaneN defiende que, entre otros, los burócratas, bureaus, y las burocracias buscan maximizar sus propias opciones y, por tanto, su «presupuesto y su actuación de output» debería ser medido.

Sin duda, ésta no es una cuestión que haya tenido mucho interés para aquellos que veían una relación entre la burocracia y la democracia. Incluso para SCHUMPETER el economista - de hecho, especialmente para él- el funcionamiento del orden democrático no podría alcanzarse si el Estado no poseyera un instrumento burocrático profesional.

Aunque pueda estar de moda dejar a un lado a WEBER hoy en día, por haber adscrito funciones orgánicas al Estado, la cuestión sigue siendo que, para WEBER, ninguna democracia podía verdaderamente anclarse o consolidarse, salvo que un Estado tuviera a su disposición una organización burocrática competente en la que pudiera confiar. La ideología contemporánea anti-estadista mantiene la visión contraria: la burocracia es antitética a la democracia. Todos los Estados modernos poseen un funcionariado público adiestrado y más o menos profesional organizado en torno a líneas jerárquicas y que operan, en términos de WEBER, de acuerdo con «reglas de cálculo 
y sin ningún tipo de consideración hacia las personas» ${ }^{81}$. Tal y como lo planteó WEBER: «Cuanto más perfectamente "deshumanizada" esté la burocracia, más consigue salir victoriosa a la hora de eliminar de los asuntos de los funcionarios cuestiones como amor, odio y todos aquellos elementos puramente personales, irracionales y emocionales que escapan al cálculo. Ésta es la naturaleza específica de la burocracia y se la estima como su especial virtud» ${ }^{82}$.

El fervor anti-estadista ha dotado de poca virtud a la burocracia. Esta institución se contempla como una institución opuesta a la democracia, o tan irrelevante o nefaria para una sociedad libre y para una economía eficiente. Es en las famosas palabras de Ronald Reagan, «no parte de la solución sino el problema». Aunque las sociedades democráticas y aquellas que están en el proceso de serlo han simpatizado con o han abrazado esta posición ideológica, no existe ninguna prueba empírica que apoye la visión de que la amputación del instrumento de Estado haga en modo alguno avanzar la causa de la democracia o impulse el desarrollo económico.

WEBER mantenía que las burocracias eran instrumentos inevitables en sociedades modernas y sociedades en vías de modernización, y que ningún Estado puede funcionar sin un eficiente instrumento burocrático. SCHUMPETER fue incluso más allá e identificó a la burocracia como un elemento indispensable para la democracia. Enumera la existencia de una burocracia profesional como una de las cinco condiciones necesarias para que exista un orden democrático. La burocracia, escribió, «no constituye un obstáculo a la democracia sino un complemento inevitable de ésta. De forma similar es un complemento inevitable al desarrollo de la economía moderna» ${ }^{83}$.

SCHUMPETER, sin embargo, advierte que «el reconocimiento del carácter inevitable de una burocracia comprensiva no solventa los problemas que surgen de ello».

Pese a todo esto, no hay forma de huir del hecho de que ninguna sociedad democrática puede preservarse sin una burocracia profesional. «En una sociedad industrial moderna, el gobierno democrático de la gobernabilidad (governance) debe ser capaz de dirigir, a todos los efectos, la esfera de la actividad pública para incluir... el servicio de una burocracia bien adiestrada, con alto standing y tradición y dotada de un fuerte sentido del deber y un no menos fuerte esprit de corps (espíritu de grupo)» ${ }^{84}$.

La acusación hecha al gobierno al señalar que a menudo es incapaz de hacer frente a las necesidades de la sociedad y que se dirige de forma ineficiente, se han convertido en una acusación bien conocida. SCHUMPETER defendió que una burocracia bien adiestrada «es la respuesta principal al argumento acerca de los amateurs del gobierno. Potencialmente, es la única respuesta a la pregunta tan a menudo oída en este país: la política democrática no ha resultado ser capaz de producir un gobierno decente de la ciudad, ¿cómo podemos esperar que la nación avance si todo... se le entrega a ella?» ${ }^{85}$.

La nuestra no es la primera época en la que se ha atacado a las burocracias por incompetencia y por sofocar la libertad. Es posible -incluso deseable - aceptar los argumentos de SCHUMPETER y WEBER respecto de la importancia de una burocracia eficiente para el orden democrático sin aceptar la visión de SCHumpeter de que la burocracia «debe ser un poder legitimado en sí mismo» ${ }^{86}$. Sin embargo, la mayor parte de las veces las burocracias han operado como fuerzas de modernización más que como obstáculos al proceso mismo de modernización. La mayor parte de lo escrito de tiempos de transición deja de lado la organización del Estado. La mayor parte de lo escrito en estos períodos de hecho da por sentado la disponibilidad de una adecuada estructura de Estado. Las transiciones pueden durar largos períodos de tiempo, incluso si existe siempre la esperanza de repetir el «milagro español» ${ }^{87}$.

Como mínimo, una democracia consolidada requiere de un Estado capaz de llevar a cabo sus funciones principales (la protección de los ciudadanos, la recaudación de impuestos, la prestación de servicios) de forma ordenada, predecible y legal. Para hacer esto, el Estado ha de tener a su disposición un instrumento capaz. Juan LINZ y Alfred STEPAN se encuentran entre los primeros estudiosos de la transición a la democracia, que señalaron la importancia de una burocracia profesional en la consolidación de una democracia. Consideran que una burocracia profesional resulta tan esencial para la consolidación democrática como una sociedad civil independiente, una sociedad políticamente autónoma, y el propio Estado de Derecho. Afirman, sea como sea, que cada uno contemple el papel del Estado, que una burocracia profesional y moderna es indispensable para la consolidación democrática.

Para proteger los derechos de sus ciudadanos, y para poder prestar otros servicios básicos que los ciudadanos reclaman, el gobierno democrático necesita ser capaz de ejercitar de forma efectiva su derecho al monopolio del uso legítimo de la fuerza en el territorio. Incluso si el Estado no tuviera otra función más que ésta, tendrían que imponer impuestos a pagar por los ciudadanos para poder a su vez pagar a la policía, a los jueces y los servicios básicos. Por tanto, la democracia moderna necesita disponer de la capacidad efectiva para dirigir, regular y extraer. Y para ello necesita un Estado que funcione y una burocracia de Estado que pueda ser utilizada por los nuevos gobiernos democráticos ${ }^{88}$.

Linz y STEPAn han puesto al día de forma esencial a SCHUM. PETER o, más bien, han hecho que SCHUMPETER resulte relevante en el proceso de la transición y consolidación democrática. A medida que se ha comenzado ese proceso y que se ha estado realizando en un número importante de sociedades en Europa (Oriental), la ausencia de una burocracia profesional se ha vuelto una cuestión cada vez más evidente. 
Lo que, sin embargo, parece ser una pregunta abierta es en qué medida los instrumentos burocráticos de los Estados en proceso de democratización, necesitan equipararse a un estricto modelo weberiano. Pero lo que es indiscutible, incluso si no se reconoce totalmente, es que tales instrumentos forman parte y son una parcela de la autoridad del Estado que resulta indispensable para preservar las libertades.

Un elemento importante en una consolidación democrática es una burocracia que comienza a operar de forma impersonal, de acuerdo con las reglas y las regulaciones conocidas, y en las que los funcionarios son capaces (u obligados) a separar sus propios intereses políticos y personales de los cargos que ocupan. Tal y como Jacek KocHANOwICZ señala, «una burocracia juega no sólo un papel técnico, sino también simbólico. Como una bandera, el himno nacional, el uniforme del ejército, o una mansión presidencial, es un símbolo a través del cual el Estado - y la nación - es percibida. Los ciudadanos que tengan que hacer frente a funcionarios ineficientes y corruptos no respetarán al Estado, y los vínculos que unen a la comunidad nacional se soltarán». KOCHANOWICZ pasa después a señalar que crear una burocracia nueva, más eficiente y más autónoma, «podría ser una forma de fortalecer la legitimidad del Estado» ${ }^{89}$.

La autoridad del Estado requiere capacidades de Estado que aseguren la legitimidad del Estado. Todo esto no es más que el instrumento para proteger los derechos individuales. Tal y como Stephen HoLmeS señaló en un apreciado ensayo sobre la debilidad del Estado ruso,

«La Rusia de hoy deja muy claro que los valores liberales se ven amenazados tan profundamente por la incapacidad del Estado como por el poder despótico. La desestadización no es la solución, es el problema en sí mismo. Porque sin un poder público de cierto tipo que funcione bien, no se podrá prevenir el daño mutuo, ni la seguridad personal... Los derechos inscritos en la Constitución de Brezhnev de 1977 quedaron desprotegidos por el aparato represivo del Estado. Los derechos inscritos en la Constitución de Yeltsin de 1993 no se ejecutan porque el Estado carece de los recursos y del propósito para hacerlo» ${ }^{90}$.

El ejemplo ruso que HoLmes analiza resalta la especial importancia de dotar al Estado en proceso de democratización de capacidades, porque la «autoridad impulsa la libertad». Tal y como él lo presenta: «Si el Estado no dispone del monopolio de la violencia, el monopolio debe revestirse sólo con funcionarios a los que el público pueda responsabilizar de su uso. El liberalismo requiere que la gente que no tenga armas pueda decir a la gente con armas qué hacer» ${ }^{91}$.

\section{El mercado versus la burocracia}

Dos visiones dominan hoy la forma en que vemos la alocación de recursos y el proceso de toma de decisiones en la sociedad capitalista contemporánea. Una de ellas se basa en la capacidad del mercado para determinar las alocaciones; y la otra acepta un papel importante del mercado, pero pide al Estado que asegure las condiciones de trabajo para este mercado.

La cuestión que debemos considerar aquí no es el Estado versus el mercado en el marco de la economía moderna. Sino, más bien, si necesita preservarse una esfera pública en una sociedad democrática o si la esfera pública debería en sí misma estar sujeta a las reglas que gobiernan a la esfera privada. Al final, esto es de lo que va todo el debate relativo a la reinvención del gobierno.

Cuando la sociedad es una sociedad enteramente dependiente del mercado, o una sociedad dependiente del patrimonialismo, entonces es una sociedad a la que el Estado exige poco. Siguiendo ese mismo razonamiento, un Estado que exige poco a una sociedad es un Estado que perderá su capacidad para obtener el apoyo necesario y que también será incapaz de llevar a cabo acciones significativas cuando surja la necesidad de hacerlo.

¿Cómo va un Estado a exigir cosas a una sociedad o a satisfacer las demandas de una sociedad de protección, orden y bienestar? La sociedad debe, en primer lugar, dotarse a sí misma de lo que Linz y Stepan llamaron un Estado «unutilizable». Pero un Estado «utilizable». es aquel que posee un aparato estatal profesional. No es una casualidad que los Estados británico y francés desarrollaran en el siglo XIX élites estatales altamente adiestradas para poder ser capaces de gobernar sus importantes imperios. Estas mismas élites también administraron sus sociedades ${ }^{92}$.

Resulta interesante señalar que un Estado patrimonial o sultanista parece, en ausencia de un orden legal racional, $\tan$ «fuerte» como Estado en el sentido de que puede decidir demasiada oposición cómo debería ser administrada la sociedad. Puede además proveer y eliminar subsidios, bienestar, y otorga a su libre albedrío. Y realiza pocas, o si acaso, ninguna exigencia. En resumen, hace mínimas las demandas de la sociedad. Tal Estado es un Estado desconectado de la sociedad y, por tanto, un Estado débil ${ }^{93}$.

$¿$ Cabe acaso entonces deducir de todo esto, tal y como señaló Carl FrIEDRICH, que un sistema constitucional surge después de que se haya establecido un aparato burocrático ${ }^{94}$. ¿O acaso se tiene que crear una burocracia profesional de forma paralela a un sistema constitucional? 
Claramente, resulta necesario diferenciar la importancia de la burocracia y la capacidad del Estado: 1) durante la fase de transición a la democracia; 2) durante la fase de consolidación, $y$, finalmente, 3) en democracias bien establecidas. Dependiendo de la fase con la que nos enfrentemos, la pregunta relativa a la importancia del aparato burocrático profesional cambia.

En la fase de transición, la cuestión esencial es: cayuda la estructura burocrática a la transición hacia la democracia?

En la fase de consolidación, la pregunta que nos interesa es ahora la siguiente: cen qué medidas permite la capacidad creciente del Estado la consolidación de las normas democráticas?

En las democracias bien establecidas la cuestión que se convierte en esencial es la siguiente: ¿es la estructura burocrática superflua ahora que la democracia y las prácticas democráticas están bien ancladas?
Todas estas tres fases de desarrollo democrático llevan aparejadas la creación o la protección del mercado, necesaria para el surgimiento y la protección de la democracia. ¿Varía la necesidad de una estructura burocrática profesional en función de la fase democrática en la que se vea inmersa la sociedad? ¿O requieren siempre el mercado y la democracia, no simplemente la conservación de la esfera pública, sino también la protección de la autoridad del Estado?

Aquel que habla de «la autoridad del Estado» está hablando del instrumento de poder del Estado, ya que un Estado no puede existir sin un instrumento de poder. Existen una multitud de instrumentos que sirven a diferentes tipos de regímenes ${ }^{95}$. ¿Pero cómo es de segura la democracia sin tener a su disposición un instrumento eficiente en el que pueda confiar? Quizás WEBER ha sido enterrado de forma algo prematura.
Traducción de Cristina AlBa MuNoz.

* Trabajo presentado en la XII Conferencia de Europeístas, Chicago, 30 de marzo-1 de abril, 2000.

** Princenton University.

1 Anunciando el Análisis de la Actuación Nacional, 3 de marzo, 1993.

2 Walter KICKERT, «Public Management in the United States and in Europe», en Walter J. M. KICKERT, Public Management and Administrative Reform in Western Europe (Cheltenham, UK: Edwar Edgar Publishing Ltd., 1997), p. 18. En cursiva en original. Ver, también, Hans BekKE, James Perry y Theo Toonen, Civil Service Systems in Comparative Perspective (Bloomington: Indiana University Press, 1996).

${ }^{3}$ Analizo ambas cuestiones en mi libro que saldrá pronto, The Transformation of the Bureaucracy in Democratic Societies.

${ }^{4}$ National Partnership for Reinventing Government (lo que, antes el National Performance Review): A Brief History (Washington, D.C., enero 1999), p. 1.

s Donald F. Kettr, Elaine Kamarck, Steven Kelman y John C. Donahue, Assessing Reinvention as a Major Reform, Ocasional paper 3-98, John F. Kennedy School of Government, Harvard University, p. 8.

${ }^{6}$ James Q. WILson, Bureacracy (New York: Basic Books, 1989), p. 10.

7 Gerald E. CaIden, Administrative Reform Comes of Age (New York: Walter de Gruyter, 1991).

${ }^{8}$ «Executive Summary», Simposio Ministerial sobre el Futuro de los Servicios Públicos, 5-6 de marzo de 1996 (Paris: OCDE, 1996).

${ }^{9}$ Vincent WRIGHT, «Reshaping the State: The Implications for Public Administration», West European Politics 17, 4 (julio 1994): pp. 10-116.

${ }^{10}$ Laurence E. LyNn, Jr. «The New Public Management as an International Phenomenon: A Skeptical View», International Public Management Joumal, 1, 1, 1998.

$"$ B. Guy Peters y Donald J. SAvol, «Civil Service Reform: Misdiagnosing the Patient», Public Administration Review 54, 5 (sept./oct. 1994: 419).

12 WRGGT: 110.

${ }^{13}$ Trend in Public Sector Pay (Paris: OCDE, 1993: 33).

${ }^{14}$ Structure of the Public Service Employment in Seven OECD Countries (Paris: OCDE, 1999).
${ }^{15}$ John Halligan, «New Public Sector Models: Reform in Australia and New Zealand», Jan-Erik Lane (ed.), Public Sector Reform, Rationale, Trends and Problems (London: Sage, 1997), p. 29.

${ }^{16}$ Christopher HooD, «"Deprivileging" the UK civil service in the 1980s: Dream or Reality?», en Jon PIERRE (ed.), Bureaucracy in the Modern State, An Introduction to Comparative Public Administration (Hants, England: Edward Elgar, 1995: 96-97).

${ }^{17}$ Michael J. Goldsmith y Edward C. PAGE, «Farewell to the British State?», en Lane (ed.), Public Sector Reform: 154.

${ }_{18}$ WRIGHT, «Industrial and Banking Privatization in Western Europe: Some Public Policy Paradoxes» (San Dominico, Florence: Robert Schumann Center at the European University Institute, 1995: 14).

19 Wright (1995): 13; David PARKER, «Privatization in the European Union. An Overview», en PARKer (ed.), Privatization in the European Union. Theory and Policy Perspectives (London: Routledge, 1998: 12).

${ }^{20}$ Tony Verhejen, «Public management Reform in New Zealand and Australia», en Tony Verheijen y David Coombes (eds.), Innovations in Public Management. Perspectives from East and West Europe (Cheltenham, UK: Edward Elgar, 1998: 262, 258); Halligan: 22-23.

${ }^{21}$ Halligan: $33-34$.

22 PARKER: $13-14$.

${ }^{23}$ Wright (1994): 111.

${ }^{24}$ Halligan: 24.

${ }^{25}$ Allan Rosas, «Indirect Public Administration: General Comment», en Tore MODEen y Rosas, Indirect Public Administration in Fourteen Countries (Abo: Abo Academy Press, 1988: 32-34).

${ }^{26}$ Philippe Keraudren, «New Public Management Reform in the United King. dom», en VeRHEJEN y COOMBES: 234-236.

${ }^{27}$ Citado en David G. Mathiasen, «The New Public Management and it's Critics», International Public Management Journal, 1, 2 (1998).

${ }^{28}$ Laurence E. LyNn, Jr., «Public Management and Government Performance: A Consideration of Theory and Evidence», Working Group of the International Public Mangement Network, Postdam, Germany 26-7 junio 1997. 
${ }^{29}$ Philipe Keraudren y Hans van Mierlo, «Theories of Public Management Reform and their Practical Implications», en Tony Verhejen y David CoOMBes: 41-42; Mathiasen.

${ }^{30}$ Kurt Klaudi KLAUSEN, «NPM in the Nordic CountriesA Vitalization of or an End to the Scandinavian Model?», International Public Management Network Meeting, 25-27 de junio 1997, Postdam.

${ }^{31}$ Keraudren y Andras B. BaKa, «France: A Different Approach to Reform», en VeRHEIJEN y COOMBES: 358.

32 Keraudren y BaKa: 359-365; Thierry Postif, «Public Sector Reform in France», en LANE: 213-215.

${ }^{33}$ Jack H. NAGEL, Introducción del Editor, Journal of Policy Analisis and Management 16, 3 (1997): 350.

34 Verheijen, «Public Management Reform in New Zealand and Australia», en VERHEIJN Y COOMBES: 257-261.

${ }^{35}$ Herman SCHWARTZ, «Small States in Big Trouble: State Reorganization in Australia, Denmark, New Zealand and Sweden in the 1980s», World Politics, 46 4 (julio de 1994): 540-542.

${ }^{36}$ Allan SCHICK, The Spirit of Reform: Managing the New Zealand State Sector in a Time of Change, Informe preparado por la Comisión de Servicios Estatales y Tesorería (Wellington, NZ 1996): 7. Citado en John Halligan, «New Public Sector Models: Reform in Australia and New Zealand», en LANE: 30.

"Rod RHODES, «Reinventing Whitehall 1979-1995», en Walter J. M. KICKERT, Public Management and Administrative Reform in Western Europe, Cheltenham UK: Edward Elgar, 1997: 43.

${ }^{35}$ Michael J. GoldSmith y Edward C. PAGE, «Farewell to the British State?», en LANE: 148-149.

${ }^{39}$ Christopher Polurtr, Managerialism and the Public Services. Cuts or Cultural Change in the 1990s?, 2. ${ }^{\mathrm{a}}$ ed. (Oxford: Blackwell Publishers, 1993: 55-56).

${ }^{40}$ RHODES: 50.

${ }^{41}$ Keraudren: 228.229.

42 RHODes: 48.

43 «Issues and Developments in Public Management: informe de 1996-1997 sobre el Reino Unido» (Paris: OCDE, 1997).

44 Helmut Wollmann, «Modernization of the Public Sector and Public Administration in the Federal Republic of Germany- (Mostly) A Story of Fragmented Incrementalism», Michio MURAMATSU y Frieder NASCHOLD (eds.), State and Administration in Japan and Germany (Berlin: de Gruyter, 1997: 80).

45 «Issues and Developments in Public Management: informe de 1996-1997 sobre Alemania» (Paris: OCDE, 1997).

${ }^{4 \vdots}$ Helmut KLAGER y Elke LÖFFLER, «Administrative modernization in Germany-a big qualitative jump in small steps», International Review of Administrative Sciences, 61 (1995): 375 .

47 Jann WERNER, «The Reform of Central Government in Germany-the Government's Move from Bonn to Berlin as a Chance for Administrative Reform», Trabajo para la conferencia «El Sector Público en Alemania y Australia: De la Jerarquía a la Gestión Contractual», 23 a 24 de enero de 1997, Univ. de Postdam.

${ }^{43}$ WERNER: 14.

49 Halligan: 24.25; Verheijen: 260-263.

5J Donald F. KETTL, «The Global Revolution in Public Management: Driving Themes, Missing Links», en Journal of Policy Analysis and Management, 163 (1997): 453.

51 KerAudren: 224.

32 VERHEIJEN: 272.

53 KETTL: 453.

54 Jeraydreb ABD JAJAL: 363-365.

ss The State of the Higher Civil Service after Reform: Britain, Canada, and the United States (Paris: OCDE, 1999).
56 VeRHEIJEN: 272.

57 LYNN (1997).

${ }^{58}$ KeTTL: $450-451$.

59 KetTL: 448.

${ }^{60}$ In Search of Results, Performance Management Practices (Paris: OCDE, 1997: 23).

${ }^{61}$ Peters y Savole: 421.

${ }^{62}$ KetTl: $447-448$.

${ }^{63}$ Keraudren: 231.232.

${ }^{64}$ Osborne y Gaebler, Reinventing Government, p. 12.

${ }^{65}$ Ibid., pp. 11-12.

${ }^{66}$ Ibid., p. 12.

${ }^{67}$ Ver Amy Gutmann y Dennis Thompson, Democracy and Disagreement (Cambridge: Harvard University, 1997).

${ }^{68}$ Robert D. Putnam, Making Democracy Work: Civic Traditions in Modern Italy (Princeton: Princeton University Press, 1993).

${ }^{69}$ Douglass C. NORTH, Institutions, Institutional Change and Economic Performance (Cambridge University Press, 1993).

${ }^{70}$ Max Weber, The Theory of Social and Economic Organization (New York: The Free Press, 1964), p. 337.

${ }^{71}$ Ibid., p. 338.

${ }^{72}$ Ibid., pp. 338-339.

${ }^{73}$ Ibid., p. 339.

${ }^{74}$ Ibid.

${ }^{75}$ Bernard S. SILBerman, Cages of Reason: The Rise of the Rational State in France, Japan, The United States, and Great Britain (Chicago: The University of Chicago Press, 1993), p. 6.

${ }^{76} \mathrm{Ibid}$.

77 William A. NisKanen, Jr., Bureaucracy and Representative Government, p. 9.

${ }^{78}$ Ibid.

79 Ver Stephen Krasner, Defending the National Interest (Princeton: Princeton University Press, 1973).

${ }^{80}$ NisKANEN, Bureaucracy and Representative Government, p. 9.

${ }^{81}$ Max Weber, «Bureaucracy», en H. H. Gertz y C. Wright Mills (eds.), From Max Weber: Essays in Sociology (New York: Oxford University Press, 1962), p. 215.

${ }^{82}$ Ibid., p. 216.

${ }^{83}$ Joseph Schumpeter, Capitalism, Socialism and Democracy, 3. ${ }^{\mathrm{a}}$ ed. (New York: Harper, 1949), p. 206.

${ }^{84}$ Ibid.

${ }^{85}$ Ibid., p. 293.

${ }^{86} \mathrm{Ibid}$.

${ }^{87}$ Ver Adam Przeworskik, Democracy and the Market: Political and Economic Reforms in Eastern Europe and Latin America (Cambridge: Cambridge University Press, 1991), p. 8.

${ }^{88}$ Juan Linz y Alfred STEPAN, Problems of Democratic Transition and Consolidation: Southern Europe, South America, and Eastern Europe (Baltimore: John Hopkins University Press, 1996), p. 11.

${ }^{89}$ Jacek Kochanowicz, «Reforming Weak States and Deficient Bureaucracies», en Joan Nelson (ed.), Intricate Links: Democrtization and Market Reforms in Latin America and Eastern Europe (New Brunswick, NJ: Transaction Publishers, 1994), p. 203.

${ }^{90}$ Stephen HoLmes, «What Russia Teaches Us Now: How Weak States Threaten Freedom», The American Prospect (julio-agosto 1997), p. 32. 
${ }^{91}$ Ibid., p. 33.

${ }_{92}$ Ver Henry PARrIs, Constitutional Bureaucracy (London: George Allen \& Unwin LTD., 1969), p. 48.

${ }^{93}$ Ver Holmes, «What Russia Teaches Us Now: How Weak States Threaten Freedom. Ver también Kiren Azız Chaudhry, The Price of Wealtb: Economies and Institutions in the Middle East (Ithaca: Cornell University Press, 1997), y H. E.
Chemabi y Juan J. Linz, Sultanistic Regimes (Baltimore: The John Hopkins University Press, 1998.)

${ }^{94}$ Carl J. Friedrich, Constitutional Government and Democracy (Boston: Ginn, 1950), pp. 25-27.

95 Chehabl y Linz, Sultanistic Regimes, Karl Wrtvogel, Oriental Despotism. 
